\title{
Establishing the interrelation of the main influencing factors on the safety of methane-air mixture transportation
}

\author{
Ruslan Ahaiev ${ }^{1, *}$, Kateryna Dudlia ${ }^{1}$, and Dmytro Prytula ${ }^{1}$ \\ ${ }^{1}$ Institute of Geotechnical Mechanics named by N. Poljakov of National Academy of Sciences of \\ Ukraine, 49005, Dnipro, Simferopolska Str., 2a, Ukraine
}

\begin{abstract}
The computing of the pipeline diameter and the decision of a vacuum pump for capturing methane-air mixture from underground wells in a real mine are presented in the article. The safety conditions for transportation of methane-air mixture are presented. The relationship between mining and mining and geological factors using regression analysis are established. These factors affect the transportation of methaneair mixture safety. The results of the work can be used in the projecting of underground degassing systems in the development of coal deposits and methane production.
\end{abstract}

\section{Introduction}

There is a shortage of gaseous energy carriers, which is caused by the limited nature of their reserves and the substance volumes lag of the consumption volumes production in the fuel and energy complex of Ukraine. The intensive technologies development of mining enterprises, an uprating of mechanized excavation harvesters and planes increase the load on the working faces, and the development of mineral resources is conducted in increasingly complex mining and geological conditions. The gas factor is the main reason for limiting the extraction of district production. In the conditions of mines with a high volume of gas, the presence of a "gas barrier" reduces the efficiency of the existing highperformance equipment. Earlier in the coal industry, the main attention was paid to improving the technology and technics of coal mining. Gas control was assigned a secondary role. Currently, the main task is to improve the safety of mining operations $[1,2]$. A secondary task is the extraction of coal mine methane during the shortage of an alternative source of energy.

About 360 million cubic meters of methane (26\%) are recovered by mine degassing systems, about $50 \%$ of which is captured and usefully used [3]. Degassing in coal mines is carried out by drilling vertical wells from the surface, as well as from mine workings to a gas-saturated coal-rock massif. To transport and evacuation of methane through metal pipelines, vacuum pumping units, and gas suction fans are used. According to the norms, the concentration of methane in the degassing pipelines should be at least $25 \%$ in a mixture with air, and the concentration of methane in the air stream leaving the mine should not

\footnotetext{
*Corresponding author: igtmdep16@gmail.com
} 
exceed $0.75 \%$ according to safety conditions [4]. It is impossible to ensure an increase in coal mining and the profitability of mines without degassing. Therefore, the establishment of the main influencing factors interrelation on the safety of transportation of methane-air mixture is relevant.

\section{Methods}

The calculation of the diameter of the pipeline and the choice of a vacuum pump for capturing methane-air mixture from underground boreholes is carried out according to [5]. Determining the interconnections of the main influencing factors on the safety of transportation of methane-air mixture is feasible with the help of multiple regressions [6].

Determine the flow of methane-air mixture in the pipeline

$$
Q_{s}=k_{r} \cdot\left(Q_{0}+k_{n} \cdot l_{w}\right), \mathrm{m}^{3} / \mathrm{min}
$$

where $k_{r}$ - the safety factor, taking into account the error of the prediction of methane emission, $k_{r}=1.25 ; Q_{0}$ - the flow of methane-air mixture at the starting point of the pipeline, $\mathrm{m}^{3} / \mathrm{min}$ (from boreholes); $k_{n}$ - coefficient taking into account the air leakage per $1 \mathrm{~m}$ of the pipeline, $10^{-3} \mathrm{~m}^{2} / \mathrm{min} ; l_{w}$ - the length of the gas pipeline working area, $\mathrm{m}$.

Determine the concentration of methane gas in the pipeline

$$
C_{a}=\frac{100 \cdot I_{0}}{Q_{0}+k_{n} \cdot l_{w}}, \%,
$$
$\mathrm{m}^{3} / \mathrm{min}$.

where $I_{0}$ - the emission of methane entering the gas pipeline at the working area,

Determine the pressure in the pipeline

$$
P_{p}=P_{b} \cdot\left(1+1.17 \cdot 10^{-4} \cdot H\right)-B_{y}, \mathrm{~mm} \mathrm{Hg}
$$

where $P_{b}$ - atmospheric pressure in the mine, measured by a barometer, $760 \mathrm{~mm} \mathrm{Hg}$; $B_{y}$ - vacuum in the borehollheads, $50 \mathrm{~mm} \mathrm{Hg} ; H$ - depth of development, $\mathrm{m}$.

Determine the unit pressure loss in the pipeline

$$
\Delta P_{u}=\frac{760-P_{m}-B_{y}}{l_{w}},(\mathrm{~mm} \mathrm{Hg}) / \mathrm{m}
$$

where $P_{m}$ - the pressure of the methane-air mixture at the suction inlet of the vacuum pump, $\mathrm{mm} \mathrm{Hg}, P_{m}=300 \mathrm{~mm} \mathrm{Hg}$ - when designing degassing systems.

Determine the diameter of the pipeline

$$
d=0.04 \cdot\left(\frac{Q_{s}{ }^{2}}{\Delta P_{u}}\right)^{0.188}, \mathrm{~m}
$$

We determine the internal diameter of the injection pipeline, which supplies the gas-air mixture from the vacuum pumping station to the boiler room. The distance from the surface degassing complex to the boiler room is $200 \mathrm{~m}$. The actual diameter of the pipeline is $273 \mathrm{~mm}$. The calculation was produced by formula [5]

$$
d_{i}=\sqrt{\frac{\left(\frac{V_{g}}{Q_{g}}+t_{g}+t_{i}\right) \cdot Q_{u}}{47 \cdot l_{g}}}, \mathrm{~m}
$$


where $V_{g}$ - the volume of the way along which the methane-air mixture passes from the place of sampling to the entrance to the gas analyzer, $\mathrm{m}^{3} ; Q_{g}$ - the flow of methane-air mixture passing through the gas analyzer, $\mathrm{m}^{3} / \mathrm{s} ; t_{g}$ - total inertia (including transport and preparation of methane-air mixture) of the gas analyzer, $s ; t_{i}$-inertia of the slam-shut valve, $0.5 \mathrm{~s} ; Q_{u}$ - the flow of methane-air mixture supplied to the user, $\mathrm{m}^{3} / \mathrm{s} ; l_{g}$ - the length of the discharge pipe, $\mathrm{m}$.

Determine the pressure methane-air mixture in the discharge pipe of the pump on formula [5]

$$
P_{i}=\Delta P_{a}+\Delta P_{d}+\Delta P_{m}+P_{g}+P_{n}, \mathrm{~mm} \mathrm{Hg}
$$

where $\Delta P_{a}$ - the pressure loss in the protective and regulating equipment, $\mathrm{mm} \mathrm{Hg} ; P_{n}$ pressure loss on flame arresters, $10 \mathrm{~mm} \mathrm{Hg} ; \Delta P_{d}$ - pressure loss at the measuring diaphragm, $5 \mathrm{~mm} \mathrm{Hg} ; \Delta P_{m}$ - pressure losses due to friction in the pipeline, $\mathrm{mm} \mathrm{Hg}$.

The pressure loss in the protective equipment determined by empirical formula

$$
\Delta P_{a}=k_{a} \cdot Q_{0}^{2} \cdot \gamma_{c}, \mathrm{~mm} \mathrm{Hg}
$$

where $k_{a}$ - the coefficient equal to 0.009 (pipe diameter of $0.273 \mathrm{~m}$ ); $\gamma_{c}$ - the density of the methane-air mixture, $\mathrm{kg} / \mathrm{m}^{3}$

$$
\Delta P_{m}=\sqrt{P_{g}^{2}+\frac{4.8 \cdot 10^{-5} \cdot l_{g p} \cdot Q_{0}^{2} \cdot \gamma_{c}}{d_{d}^{5.33}}}-P_{g}, \mathrm{~mm} \mathrm{Hg}
$$

where $P_{g}$ - the methane-air mixture pressure in the burners, $\mathrm{mm} \mathrm{Hg} ; l_{g p}$ - the length of the injection pipeline, $\mathrm{m} ; d_{d}$ - the diameter of the injection pipeline, $\mathrm{m}$.

The pressure in the discharge nozzle of a vacuum pump can exceed atmospheric pressure by no more than $180 \mathrm{~mm} \mathrm{Hg}$

$$
P_{i}-P_{b}<180 \mathrm{~mm} \mathrm{Hg}-\text { the compliance condition }
$$

Determination of the degree of influence of the parameters of the meta-air mixture under these conditions will be carried out using the multiple regression equation.

The multiple regression equation can be represented as

$$
Y=f(\beta, X)+\varepsilon
$$

where $X=X\left(X_{1}, X_{2}, \ldots, X_{m}\right)$ - the vector of independent (explaining) variables; $\beta$ - the vector of parameters (to be determined); $\varepsilon$ - a random error (deviation); $Y$ - dependent (explained) variable. The theoretical linear multiple regression equation is

$$
Y=\beta_{0}+\beta_{1} X_{1}+\beta_{2} X_{2}+\ldots+\beta_{m} X_{m}+\varepsilon
$$

where $\beta_{0}$ - the free term that determines the value of $Y$, in the case when all explanatory variables $X_{j}$ are 0 .

The empirical multiple regression equation can be represented as

$$
Y=b_{0}+b_{1} X_{1}+b_{2} X_{2}+\ldots+b_{m} X_{m}+e
$$

where $b_{0}, b_{1}, \ldots, b_{m}$ are estimates of the theoretical values of the $\beta_{0}, \beta_{1}, \beta_{2}, \ldots, \beta_{m}$ regression coefficients (empirical regression coefficients); $e$ - the deviation estimate of $\varepsilon$. When the assumptions of the least squares method (LSM) with respect to $\varepsilon_{\mathrm{i}}$ errors, estimates of the $b_{0}, b_{1}, \ldots, b_{m}$ parameters of the $\beta_{0}, \beta_{1}, \beta_{2}, \ldots, \beta_{m}$ parameters of the multiple linear regression are unbiased, efficient and consistent. LSM is used to estimate the parameters of the multiple regression equation. 
According to the Fisher-Snedecor distribution tables, the critical value of the $F$ criterion $\left(F_{\text {tabl }}\right)$ is found. To do this, set the level of significance $\alpha$ (usually it is taken equal to 0.05$)$

$$
F_{c}=\frac{\sum\left(Y_{i c}-Y_{a c}\right)^{2}}{m} \cdot \frac{n-m-1}{\sum\left(y_{i}-Y_{i c}\right)^{2}}
$$

where $Y_{i c}$ - the calculation value of the resulting model $Y, \mathrm{~mm} \mathrm{Hg} ; Y_{a c}$ - average value of the of the resulting model $Y$; $y_{i}$ - original value of $y, \mathrm{~mm} \mathrm{Hg} ; m$ - the number of factors, pieces; $n$ - the number of observations, pieces.

If the actual value $F_{c}>F_{\text {tabl }}$, then the coefficient of determination is statistically significant and the regression equation is statistically reliable.

\section{Results and discussion}

The safety of transportation of methane-air mixture (MAM) through the underground degassing system depends on mining-geological and mining-technical parameters. Consider the effect of the parameters of the MAM on the safety of the degassing system on the example of data ME "Sukhodolske-East".

According to the degassing standard, the transportation of the methane-air mixture is carried out through the degassing pipes laid through the mine workings and is carried out by creating a vacuum pump. Perform a calculation of the diameter of the pipeline and the choice of a vacuum pump for capturing methane-air mixture from underground boreholes. The design scheme of the underground pipeline 24 of the western sloping working face (WSW) is shown in Figure 1.

The initial data for the calculation are presented in Table 1.

Table 1. The results of the calculation.

\begin{tabular}{|c|c|c|c|c|c|c|c|c|c|c|c|}
\hline $\begin{array}{c}Q_{0}, \\
\mathrm{~m}^{3} / \mathrm{min}\end{array}$ & $\begin{array}{c}l_{w}, \\
\mathrm{~m}\end{array}$ & $\begin{array}{c}I_{0}, \\
\mathrm{~m}^{3} / \mathrm{min}\end{array}$ & $\begin{array}{c}H, \\
\mathrm{~m}\end{array}$ & $\begin{array}{c}V_{g}, \\
\mathrm{~m}^{3}\end{array}$ & $\begin{array}{c}Q_{g}, \\
\mathrm{~m}^{3} / \mathrm{s}\end{array}$ & $\begin{array}{c}Q_{u}, \\
\mathrm{~m}^{3} / \mathrm{s}\end{array}$ & $\begin{array}{c}l_{g}, \\
\mathrm{~m}\end{array}$ & $\begin{array}{c}\gamma_{c}, \\
\mathrm{~kg} / \mathrm{m}^{3}\end{array}$ & $\begin{array}{c}P_{g}, \\
\mathrm{~mm} \mathrm{Hg}\end{array}$ & $\begin{array}{c}l_{g p}, \\
\mathrm{~m}\end{array}$ & $\begin{array}{c}d_{d}, \\
\mathrm{~m}\end{array}$ \\
\hline 38.1 & 4000 & 18.1 & 990 & 46.8 & 0.64 & 1.07 & 200 & 1.26 & 770 & 200 & 0.273 \\
\hline
\end{tabular}

The results of the calculation will be presented in a Table 2 .

Table 2. The results of the calculation.

\begin{tabular}{|c|c|c|c|c|c|c|c|c|}
\hline $\begin{array}{c}Q_{s}, \\
\mathrm{~m}^{3} / \mathrm{min}\end{array}$ & $\begin{array}{c}C_{a}, \\
\%\end{array}$ & $\begin{array}{c}P_{p}, \\
\mathrm{~mm} \mathrm{Hg}\end{array}$ & $\begin{array}{c}\Delta P_{u}, \\
(\mathrm{~mm} \mathrm{Hg}) / \mathrm{m}\end{array}$ & $\begin{array}{c}d, \\
\mathrm{~m}\end{array}$ & $\begin{array}{c}d_{i}, \\
\mathrm{~m}\end{array}$ & $\begin{array}{c}\Delta P_{a}, \\
\mathrm{~mm} \mathrm{Hg}\end{array}$ & $\begin{array}{c}\Delta P_{m}, \\
\mathrm{~mm} \mathrm{Hg}\end{array}$ & $\begin{array}{c}P_{i}, \\
\mathrm{~mm} \mathrm{Hg}\end{array}$ \\
\hline 52.63 & 43 & 798 & 0.1025 & 0.272 & 0.092 & 31.41 & 21.71 & 838.13 \\
\hline
\end{tabular}

The pressure in the discharge nozzle of a vacuum pump can exceed atmospheric pressure by no more than $180 \mathrm{~mm} \mathrm{Hg}$ :

$$
P_{i}-P_{b}=838.13-760=77.41 \leq 180 \mathrm{~mm} \mathrm{Hg}-\text { condition performed }
$$

In these conditions, we will study the changes in the parameters of the methane-air environment and their influence on the safety of the degassing system.

To do this, among the number of participating parameters (factors), it is necessary to select those that we can control. These include the following factors: the flow of the methane-air mixture, the length of the gas pipeline, the atmospheric pressure in the mine, the depth of the mining, the density of the methane-air mixture and the diameter of the pipeline that affects all of this.

Determine the degree of influence of factors methane-air mixture, which are taken into 
account when determining the optimal diameter of the pipeline (Table 3).

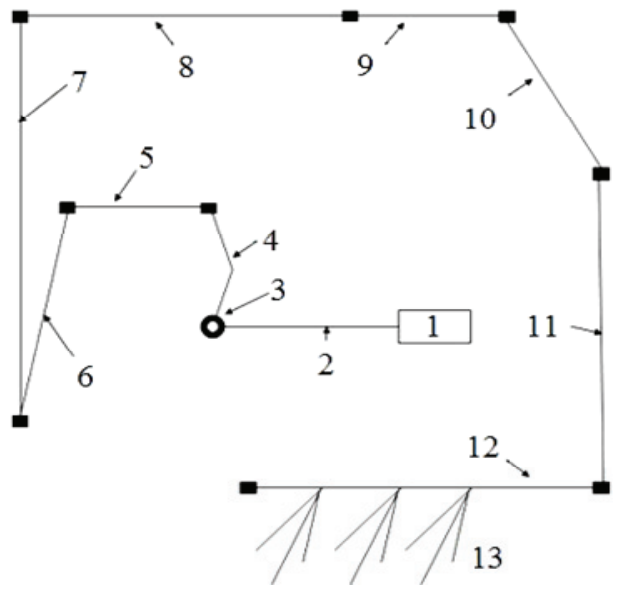

Fig. 1. Scheme of the underground pipeline 24 WSW: 1 - vacuum pump station; 2 - surface gas pipeline $l=50 \mathrm{~m} ; 3$ - borehole «1175» $l=915 \mathrm{~m} ; 4$ - degassing passage $l=30 \mathrm{~m} ; 5$ - air passage $l=$ $70 \mathrm{~m} ; 6$ - air winze $l=40 \mathrm{~m} ; 7$ - conveyor incline $l=300 \mathrm{~m} ; 8$ - east main conveyor drift $l=495 \mathrm{~m}$; 9 - west conveyor drift $l=150 \mathrm{~m} ; 10$ - roadway with separate air ventilation $l=150 \mathrm{~m} ; 11$ - west flank air passage $\# 23 l=900 \mathrm{~m} ; 12-24$ west air drift $l=900 \mathrm{~m} ; 13$ - boreholes.

Table 3. Factors affecting the diameter of the pipeline.

\begin{tabular}{|c|c|c|c|c|c|c|c|}
\hline \multirow{2}{*}{$\#$} & $P_{i}-P_{b}, \mathrm{~mm} \mathrm{Hg}$ & $Q_{0}, \mathrm{~m}^{3} / \mathrm{min}$ & $l_{w}, \mathrm{~m}$ & $P_{b}, \mathrm{~mm} \mathrm{Hg}$ & $H, \mathrm{~m}$ & $\gamma_{c}, \mathrm{~kg} / \mathrm{m}^{3}$ & $d, \mathrm{~m}$ \\
\cline { 2 - 8 } & $y$ & $x_{1}$ & $x_{2}$ & $x_{3}$ & $x_{4}$ & $x_{5}$ & $x_{6}$ \\
\hline 1 & 62.46 & 47.1 & 4247 & 760 & 990 & 1.28 & 0.292 \\
\hline 2 & 49.58 & 40 & 4000 & 755 & 950 & 1.27 & 0.277 \\
\hline 3 & 67.9 & 50 & 4200 & 764 & 824 & 1.29 & 0.299 \\
\hline 4 & 30.63 & 26 & 3700 & 762 & 550 & 1.26 & 0.235 \\
\hline 5 & 20.23 & 15.1 & 2500 & 758 & 632 & 1.2 & 0.18 \\
\hline 6 & 18.9 & 12 & 2356 & 758 & 458 & 1.1 & 0.165 \\
\hline 7 & 15.79 & 5 & 2156 & 758 & 350 & 1.05 & 0.125 \\
\hline 8 & 15.19 & 1.1 & 1980 & 760 & 300 & 1.4 & 0.089 \\
\hline 9 & 15.09 & 1.1 & 1000 & 760 & 100 & 1.4 & 0.068 \\
\hline 10 & 25.51 & 23 & 800 & 765 & 700 & 1.32 & 0.162 \\
\hline 11 & 35.83 & 33 & 500 & 765 & 750 & 1.32 & 0.169 \\
\hline 12 & 43.92 & 38 & 2400 & 770 & 824 & 1.26 & 0.244 \\
\hline 13 & 59.03 & 47 & 2650 & 760 & 825 & 1.27 & 0.268 \\
\hline 14 & 70.91 & 53 & 2950 & 760 & 840 & 1.27 & 0.286 \\
\hline 15 & 83.93 & 59 & 3125 & 760 & 890 & 1.27 & 0.301 \\
\hline 16 & 93.12 & 63 & 3400 & 760 & 900 & 1.26 & 0.314 \\
\hline 17 & 95.87 & 64 & 3560 & 770 & 1000 & 1.26 & 0.318 \\
\hline 18 & 103.47 & 67 & 3660 & 762 & 1050 & 1.26 & 0.325 \\
\hline 19 & 106.29 & 68 & 3780 & 762 & 1090 & 1.26 & 0.329 \\
\hline 20 & 117.21 & 72 & 3950 & 763 & 1120 & 1.26 & 0.339 \\
\hline 21 & 159.18 & 85 & 4150 & 758 & 1250 & 1.29 & 0.364 \\
\hline 22 & 169.04 & 88 & 4150 & 758 & 1250 & 1.29 & 0.364 \\
\hline 23 & 122.98 & 73 & 4500 & 758 & 1300 & 1.29 & 0.344 \\
\hline 24 & 122.98 & 88 & 6000 & 758 & 1300 & 1.29 & 0.344 \\
\hline
\end{tabular}


When determining the multiple regression model the main task was to set a safety condition for the difference in pressure; therefore, some parameters varied independently of boundary conditions.

Determine the matrix of paired correlation coefficients, the number of observations 24 .

Table 4. Matrix of paired correlation coefficients.

\begin{tabular}{|c|c|c|c|c|c|c|c|}
\hline & $Y$ & $X_{1}$ & $X_{2}$ & $X_{3}$ & $X_{4}$ & $X_{5}$ & $X_{6}$ \\
\hline$Y$ & 1 & 0.960 & 0.716 & -0.102 & 0.890 & 0.137 & 0.893 \\
\hline$X_{1}$ & 0.960 & 1 & 0.755 & -0.005 & 0.952 & 0.127 & 0.959 \\
\hline$X_{2}$ & 0.716 & 0.755 & 1 & -0.276 & 0.746 & -0.069 & 0.822 \\
\hline$X_{3}$ & -0.102 & -0.005 & -0.276 & 1 & -0.020 & 0.178 & -0.012 \\
\hline$X_{4}$ & 0.890 & 0.952 & 0.746 & -0.020 & 1 & 0.072 & 0.941 \\
\hline$X_{5}$ & 0.137 & 0.127 & -0.069 & 0.178 & 0.072 & 1 & 0.003 \\
\hline$X_{6}$ & 0.893 & 0.959 & 0.822 & -0.012 & 0.941 & 0.003 & 1 \\
\hline
\end{tabular}

If there is an inter-factor correlation coefficient in the matrix $r_{X j X i}>0.7$, then there is multicollinearity in this multiple regression model. In our case, $r_{X 1 X 2}, r_{X 1} X_{4}, r_{X 1 X 6}, r_{X 2 X 4}$, $r_{X 2 X 6}, r_{X 4 X 6}$ have $|r|>0.7$, which indicates the multicollinearity of the factors and the need to exclude one of them from further analysis. Analysis of the first row of this matrix allows for the selection of factor signs that will be included in the model of multiple correlation dependence

$$
Y=-4.732+1.621 \cdot X_{1} .
$$

Let's check by Fisher's criterion, according to which the calculated value, after selecting the factor, was 260.66 with $m=1$ (since we have selected one factor). The tabular value of the Fisher criterion $F_{\text {tabl }}=2.068658$ with $\alpha=0.05$.

$F_{c}>F_{t a b l}$, the coefficient of determination is statistically significant and the regression equation is statistically reliable.

For a visual assessment of the obtained regression model, we compare its values with the original values (Fig. 2).

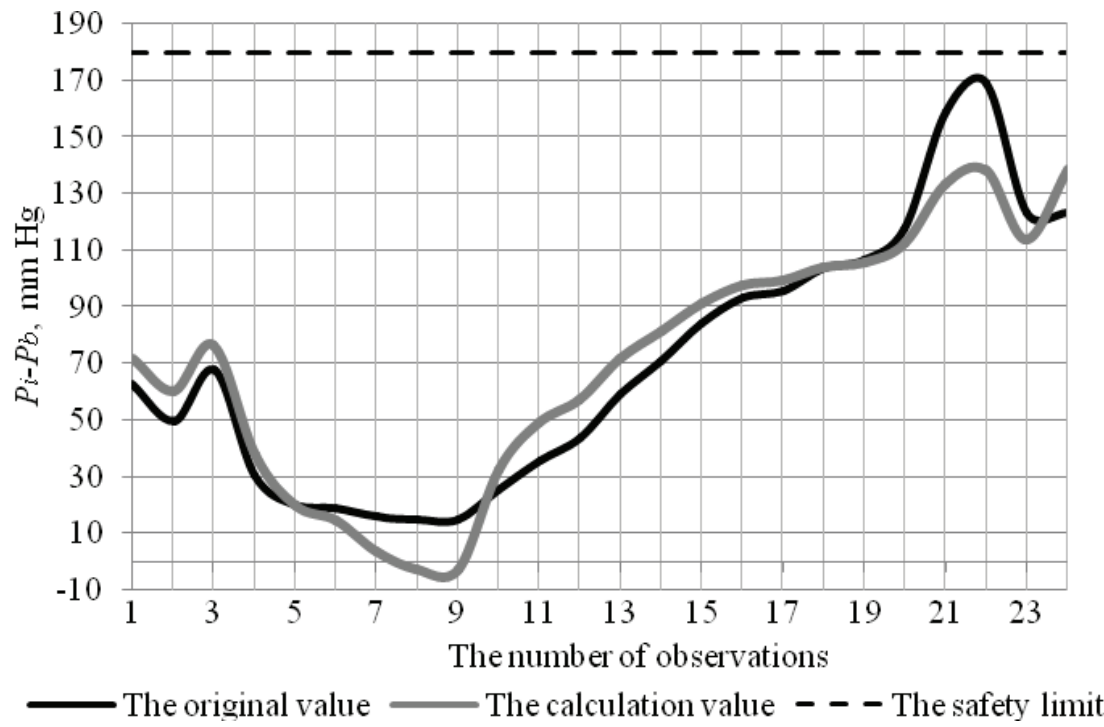

Fig. 2. Dynamics of changes in the pressure of the methane-air mixture of original and value calculation. 
As can be seen from Figure 2, the resulting model of value calculation corresponds to the original data of value original and is described with an accuracy of $95 \%$.

\section{Conclusions}

In determining the interrelation of the main influencing factors on the safety of methane-air mixture transportation, it has been established that the factor of consumption of methane-air mixture at the starting point of the gas pipeline has the maximum effect. As a result, a linear multiple regression of the form $Y=-4.732+1.621 \cdot X_{1}$ was obtained, allowing to establish the effect of the flow of methane-air mixture at the starting point of the gas pipeline (flow of borehole) on the safety of transportation of methane-air mixture.

The results make it possible to predict changes in the safety conditions of transportation of the methane-air mixture, and subsequently to manage them when changing the flow of methane from boreholes for the purpose of uninterrupted and trouble-free operation of the degassing system and the mine as a whole.

\section{References}

1. Bryukhanov, A.M. (2013). Coal mine methane and explosion safety of coal mines. Sposoby ta zasoby stvorennia bezpechnykh $i$ zdorovykh umov pratsi $u$ vuhilnykh shakhtakh, 1 (31), 12-21

2. State normative act on labor protection 1.1.30-1.01 - 00. (2000). Pravyla bezpeky $u$ vuhilnykh shakhtakh

3. Agaiev, R., Vlasenko, V., Dudlia K., Kyrychenko M., Prytula D. (2017). On the possibility of coalbed methane extraction as a source of energy under the hydrodynamic impact on the outburst coal seam. Advanced Engineering Forum Submitted, 25, 106-112

4. Vlasenko, V., Gavrilov, V., Moskovskiy, O. (2015). Influence of hydrodynamic impact on degassing of a steep coal seam at the top of the overhead longwall, New developments in mining engineering Theoretical and practical solutions of mineral resources mining, CRC Press/Balkema: EN Leiden, The Netherlands, 369-372

5. Standard of the organization of Ukraine 10.1.00174088.00. (2004). Dehazatsiia vuhilnykh shakht. Vymohy do sposobiv $i$ skhem dehazatsii

6. Voronina, O.A., Yeremenko. V.T. (2011). Eksperyment, planuvannia, provedennia, analiz: navchalno-metodychnyy kompleks 